MATEC Web of Conferences 9, 03008 (2013)

DOI: $10.1051 /$ matecconf/20130903008

(C) Owned by the authors, published by EDP Sciences, 2013

\title{
Experimental investigation of flame impingement on vertical and inclined glazing facades
}

\author{
Michael Quinn, Ali Nadjai, Faris Ali and Dimitri Bakirtzis
}

FireSERT, University of Ulster, Block 27, BT370QB, County Antrim, Northern Ireland

\begin{abstract}
Breakage and fallout of glazing systems create openings in an enclosure that affect the fire growth and the development of post flashover flames emerging outside of the openings. The behaviour of glazing is the result of its thermally induced stress response to the heat fluxes from the fire in an enclosure. In recent times building façade designs have evolved and now incorporate many different shapes, orientations and materials. The conventional single and double glazing panels have been surpassed by composite type glazing systems which include glazing and transparent resins. This paper presents experimental testing of these composite glazing panels subjected to localized fires, which have the same fire load. The effect of localized fire on the materials tested as seen in the final char patterns on both glazing systems is noteworthy. The paper also includes details of comparative calculations with EN 1991-1-2. Furthermore, results of detailed material analysis testing of the intermediate transparent resin within the glazing sandwich panels are included.
\end{abstract}

\section{INTRODUCTION}

It is known that many high rise building fires spread from floor to floor due to weaknesses which exist in the external glazing facade. Fire is an unpredictable phenomenon, the presence of the ignition source, fuel and adequate oxygen are all equally important to sustain combustion. In a compartment fire were oxygen may be scarce, the ability of a fire to generate cracks in external glazing systems due to increased thermal stresses can result in an increased level of oxygen availability which in turn has a major effect on the heat release rate of the fire. This scenario was studied previously by Pagni [1]. Research by Shields [2] also predicted that an island must be created in the glazing panel prior to the vent scenario. A large amount of experimental and numerical research has been conducted in relation to temperature and stress distribution in glass. Pagni [1] predicted that a temperature difference of $58^{\circ} \mathrm{C}$ across a glazing panel would lead to the initiation of cracks. Keski-Rahkonen [3] predicted that a temperature difference of approximately $80^{\circ} \mathrm{C}$, across the glazing was required for the initiation of cracking. This difference in first crack temperature was due to variable assumptions being made by both researchers as to glazing properties at elevated temperatures. The majority of the research previously conducted was using conventional single or double glazing samples, set up in the vertical plane to replicate the predominant vertical facade scenarios of the time. The tests presented in this paper are cognisant of recent advances in building facade design, as shown in Figure 1.

\section{EXPERIMENTAL TEST SET UP}

In order to create an accurate representation of the built facade scenario and to gain maximum return in terms of data acquisition from each test, two glazing panels having different orientations, $90^{\circ}$ and $75^{\circ}$ were subjected to localized fire which may be representative of a real life compartment fire scenario.

This is an Open Access article distributed under the terms of the Creative Commons Attribution License 2.0, which permits unrestricted use, distribution, and reproduction in any medium, provided the original work is properly cited. 

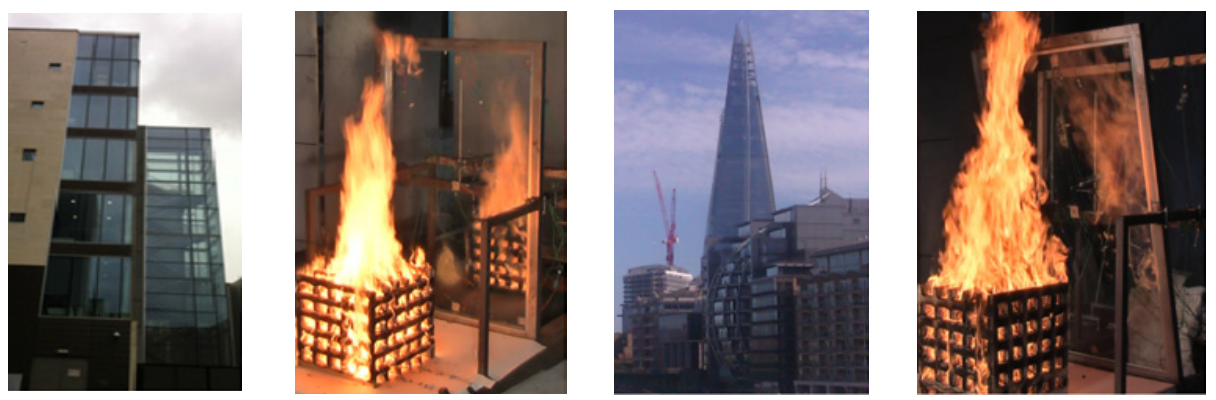

Figure 1. As built and test scenarios.
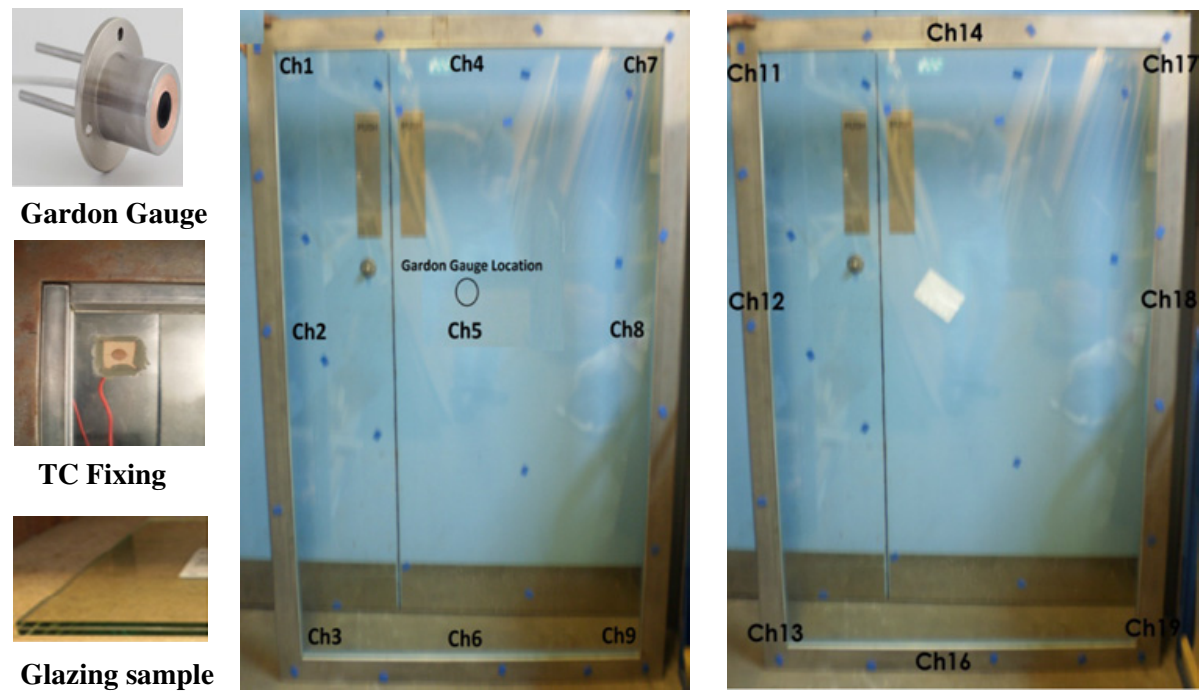

Figure 2. Glazing panel system and instrumentation.

The glazing used in these experimental fire tests was Pyroguard Fire Resisting Glass. [4] This glazing panel is $1 \mathrm{~m}(\mathrm{w}) \times 1.5 \mathrm{~m}(\mathrm{~h})$ and $7.2 \mathrm{~mm}$ in thickness and is made up of 2 layers of $3 \mathrm{~mm}$ glass, and an intermediate layer of $1.2 \mathrm{~mm}$ transparent epoxy resin as shown in Figure 2. [4] This resin plays a significant role in the glazing's thermal integrity and performance at elevated temperatures.

The thermocouples used in these experiments were small pad type K. In order to ensure that the thermocouples had an ideal connection with the test specimen, the thermocouple was lodged within a small rectangular piece of fiberboard as per Figure 2. This fiberboard and thermocouple combination was then fixed to the unexposed side of the test specimen and the stainless steel frame using a fire resistant grout, and left to cure. In the inclined test the position of the panel was 15 degrees off the vertical. A Gardon gauge to permit the measurement of heat flux in $\mathrm{kW} / \mathrm{m}^{2}$ was located centrally on the non-fire side of the test specimen $65 \mathrm{~mm}$ from the unexposed face in the vertical plane, and $85 \mathrm{~mm}$ above the centerline on the horizontal plane. The softwood timber fuel was set up in a $0.5 \mathrm{~m} \times 0.5 \mathrm{~m} \times 0.5 \mathrm{~m}$ crib format. The crib was positioned centrally 0.5 metres from the face of the glazing panel as per Figure 3 . During the tests a fan was placed centrally and a distance of 1 metre from the back face of the crib (2 metres from glazing). The wind speed measured from the fan at the flame region was $1.5 \mathrm{~m} / \mathrm{s}$. 
$1^{\text {st }}$ International Seminar for Fire Safety of Facades, Paris (France), 2013
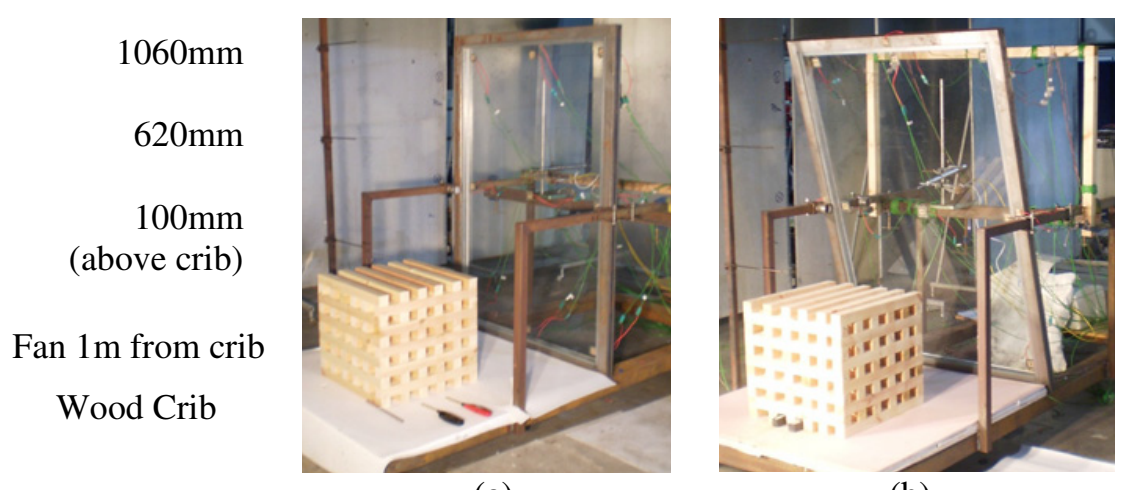

(a)

(b)

Figure 3. (a) Vertical and (b) inclined experimental test arrangement.

\section{EXPERIMENTAL RESULTS}

A vast amount of data has been accumulated during the completion of the two experimental tests set out briefly above. The data collected in the tests included; unexposed glazing temperatures, unexposed steel frame temperature, flame region temperatures, heat flux recordings and heat release rates. From a review of the heat release rate outputs for each test, it is clear that both test fire loads were identical with a very similar heat release rate.

When the heat flux recordings from the non fire side of each of the glazing panels are assessed it is clear that the inclined test had a faster initial growth rate in terms of heat flux when compared to the vertical test, as may be expected due to the fact that the flames from the crib were closer to the glazing panel in the early stages of the inclined test given the orientation of the panel. This rapid growth did not continue, in fact the curve went below the vertical test curve, with a sizeable difference in value at approximately 25 minutes. This occurrence is due to the fact that a large amount of the resin within the glazing panel of the inclined test had already activated at this time, due to the constant direct attack of the flames, which was not the case in the vertical test. In essence the area of glazing between the flame and the Gardon gauge in the inclined test had converted to a black shield of resin resulting in the inability of the radiation of the flame to reach the gauge. The first crack times in both tests were also recorded, in the vertical test the first crack occurred at 10 minutes whilst the inclined test first crack occurred at 7 minutes. This further emphasizes the greater severity of the flames and heat on the inclined test glazing panel even though the fire loads and heat release rates in both tests were almost identical.

As discussed previously there were nine thermocouples placed on the unexposed side of the glazing panels. It is noted from a review of the temperature data collected from the glazing samples during the tests Figures 4 (a) and (b), that as expected the hottest region was up the centre of each panel vertically. The maximum glazing temperature recorded in both tests was in the region of $275-300{ }^{\circ} \mathrm{C}$ at approximately 28 minutes, although not in the same glazing location in both tests. The time of 28 minutes noted above was also the approximate time in each test when the Heat Release Rate was at its peak.

It was expected that the area adjacent the wood crib would be the hottest in each test, this proved to be the case in the vertical glazing test. However during the inclined glazing test, it was observed that the flames actually came in contact with the top section of the panel for long periods due to the panel orientation. The scenario of flame contact in the inclined test inevitably lead to this region of the inclined glazing panel recording the highest glazing temperatures, this however was not the case in the vertical glazing test. It was also observed during the inclined test that some of the resin within the glazing panel began to ignite and produce flaming at approximately 19 minutes into the test. 


\section{MATEC Web of Conferences}

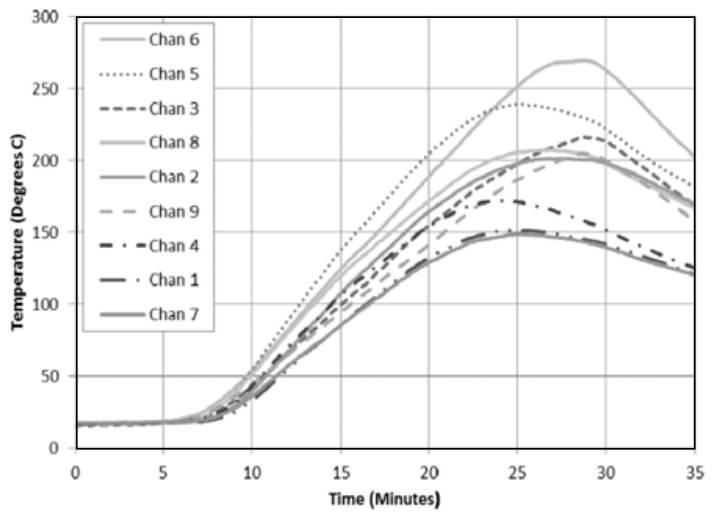

(a)

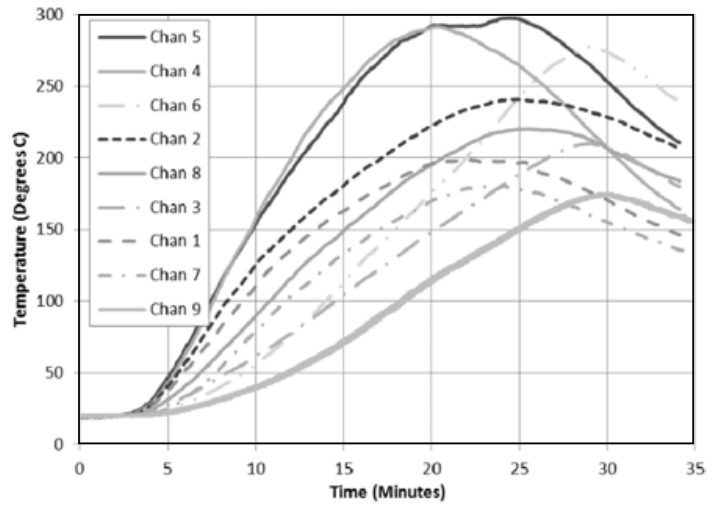

(b)

Figure 4. Vertical and (b) inclined glazing test temperatures.

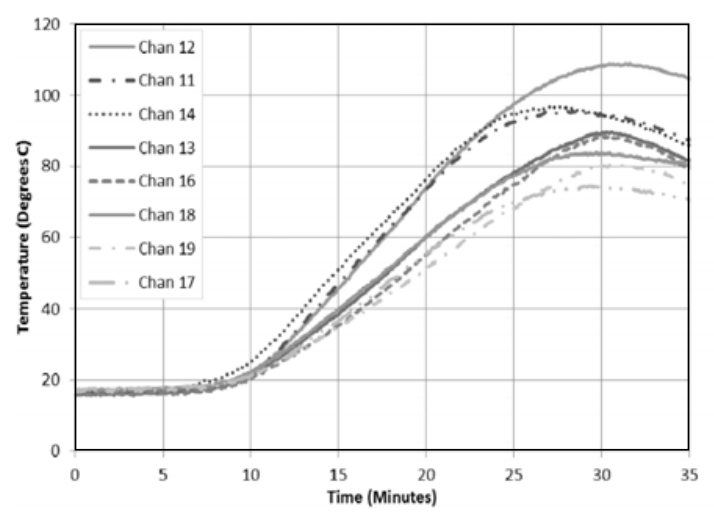

(a)

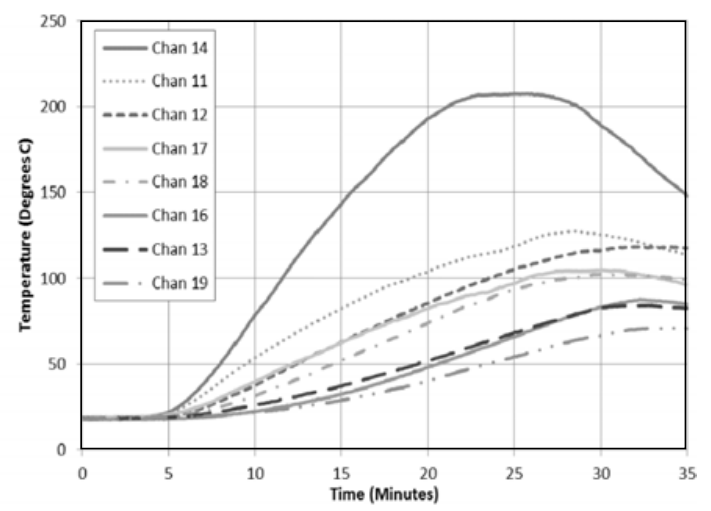

(b)

Figure 5. (a) Vertical and (b) inclined glazing panel steel frame temperatures.

There is a considerable difference in temperature evolution at the top of each glazing panel, with the inclined test exhibiting much higher temperatures as would be expected given the direct flame contact during the test. The temperature evolution at the bottom of each panel is not that dissimilar given that both locations are practically the same distance from the burning crib in each test. Included in Figures $5 \mathrm{a}$ and $\mathrm{b}$ below is the steel frame temperatures recorded during each test.

Upon review of the recorded steel temperatures it can be seen that at no point in either test do the steel temperatures reach a value were one might become concerned about steel deformation. The data provides confidence that the integrity of the steel frame remains unaffected by the elevated temperatures in both the vertical and inclined tests.

An interesting record taken during each test was the heat flux transmitted from the fire to a Gardon gauge. The curves below in Figure $6 \mathrm{a}$ are heat flux evolutions from a number of vertical panel tests. Test 1 and Test 2 curves in Figure 6a are from experiments were the Gardon gauge was subjected to the complete thermal radiation of the fire whereas Test 4 is a curve resultant from a Gardon gauge placed behind the glazing panel on the non fire side. It is clear when the curves are compared that the Gardon gauge behind the glazing does not receive the same level of radiation, therefore we can conclude that the 


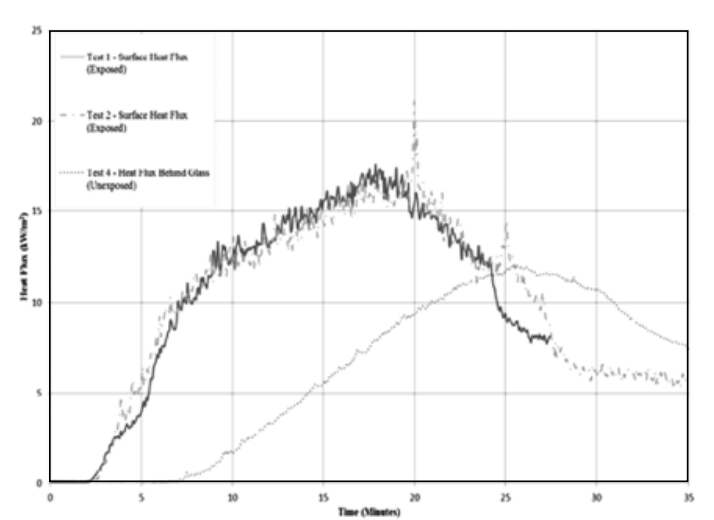

(a)

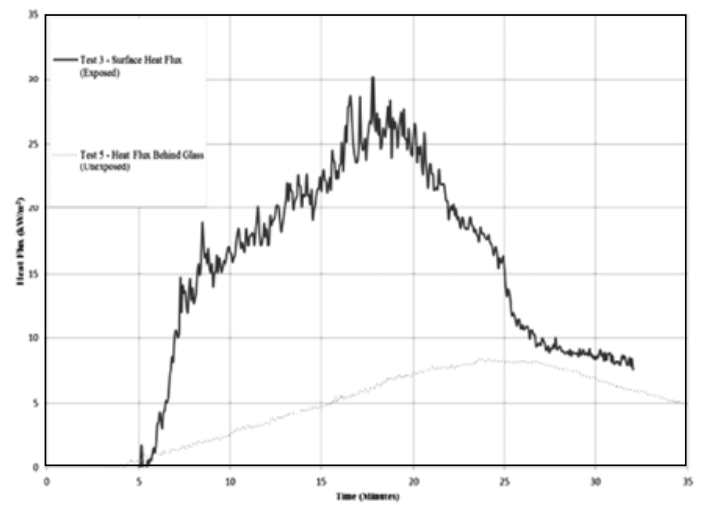

(b)

Figure 6. (a) Vertical and (b) inclined tests heat flux comparison.

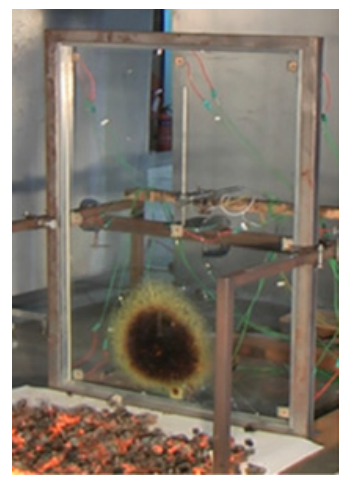

(a)

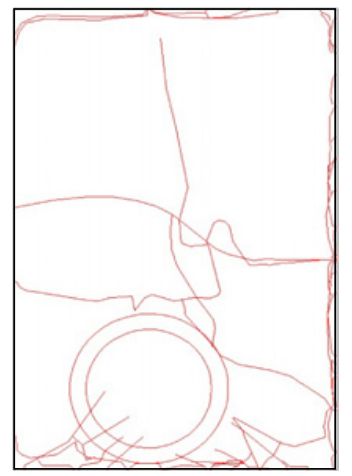

(b)

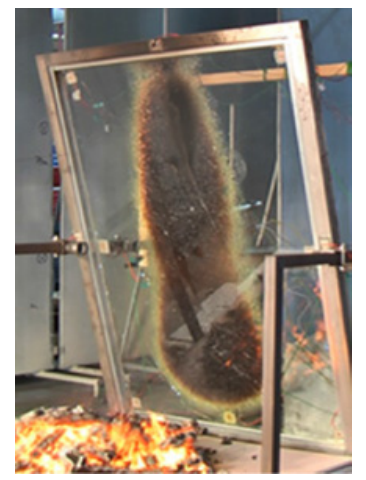

(c)

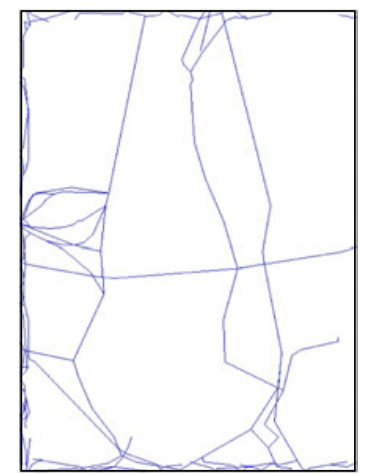

(d)

Figure 7. (a) \& (c) Vertical \& inclined post-test pictures, (b) \& (d) vertical \& inclined test cracks.

glazing panel absorbs and reflects some of the radiation away prior to it being transmitted through the glazing to the Gardon gauge. The same can be said for the inclined test comparisons made in Figure 6b, where there is also a considerable difference in the heat flux recordings for the Gardon gauge exposed to the flames and that of the gauge placed on the non-fire side of the glazing panel.

The illustrations contained in Figures $7 \mathrm{a}-\mathrm{d}$ show the post-test crack and char patterns for both the vertical and inclined tests. It is interesting to note that both scenarios produce dramatically different results. It can be concluded that the inclined fire was much more severe on the glazing and is therefore the critical scenario in terms of glazing performance. It was observed during the inclined test in particular that upon initial glazing cracking smoke and flaming emanated from the intermediate resin layer. A detailed glazing crack analysis was conducted after each test and it was interesting that the cracks were not consistent on both sides of the same glazing panel. This would suggest that the panel itself acts as a composite system with the intermediate resin a very important element of the system. Although there was considerable cracking evident on both sides of each panel the intermediate resin layer performed well in that it held the cracked glazing in place with no holes apparent in either panel. 


\section{MATEC Web of Conferences}

\section{EUROCODE CALCULATIONS - EN 1991-1-2}

It is interesting as part of this research to conduct some comparative exercises between the data recorded during the experimental tests and that of published mathmatical corellations in recognised and approved standard documents. In this instance, Euro-code 1991-1-2 will be reviewed and used to assess its accuracy with that of some of the recorded data form the experimental tests.

The main paprameter used in the mathmatical correlations within this eurocode is the heat release rate. Given that the heat release rate was recorded during each of the experimental tests, that data will be implemented into the corellations to be explained in more detail below. Another paramater of interest is the flame thickness $(D)$ which is asumed to be $0.5 \mathrm{~m}$ the same width as the fuel source.

It is stated in EN 1991-1-2 that a localised fire is a fire in which flashover is unlikely to occur, a fire which involves a limited fire load. It is appearant that the height of the flames are important and must be assesed. The flame height is dependant on the dimensions of the fuel source and the heat release rate of the fire and can be calculated as shown in Equation (1).

$$
L_{f}=-1.02 x D+0.0148 x Q^{2 / 5} .
$$

Where $D(\mathrm{~m})$ is the flame thickness, and $Q(W)$ heat release rate. When the flame is not impinging on the ceiling of a compartment $\left(L_{f}<H\right)$, or in the case of fire in open space, the temperature $\theta_{z}$ in the plume along the symetrical vertical flame axis is given by Equation (2) and Equation (3).

$$
\begin{gathered}
\theta_{z}=20+0.25 x Q_{c}^{2 / 3} x\left(z-z_{0}\right)^{-5 / 3} \leq 900, \\
z_{0}=-1.02 x D+0.00524 x Q^{2 / 5} .
\end{gathered}
$$

Where $Z_{0}$ is the virtual origin. $Q_{c}$, the convection element of the heat release rate is set to $70 \%$, of the total according to Eurocode. From review of the Eurocode there is no equation present for $\theta_{z}>900$. Therefore, a linear relation is asumed for ther lower regions from $900^{\circ} \mathrm{C}-1200^{\circ} \mathrm{C}$ as given by Equation (4).

$$
\theta_{z}=-\frac{300 x z}{\left(\frac{900-20}{0.25 x Q_{c}^{2 / 3}}\right)^{-3 / 5}+z_{0}}+1200 .
$$

Using the heat release rate data recorded during each test and other test particulars it is possible to calculate the plume centerline temperatures at predefined heights. A comparative exercise can then be conducted to establish the accurancy of the calculated results with the recorded flame temperatures. In order to present the comparison between the recorded and calculated flame temperatures the thermocouple placed centrally within the flame, $0.620 \mathrm{~m}$ above the wood crib and $1.12 \mathrm{~m}$ from the base of the fire is used. (i.e. mid-flame) It can be seen from a review of both the vertical and inclined results Figures $8 \mathrm{a}$ and $8 \mathrm{~b}$ respectively that there is some differences between the recorded and calculated values for each test, particularly in the transition from growth to steady state were the recorded value is considerably higher than that calculated using EN 19911-2 for both tests. This trend then reverts in the decay stage of both tests with the recorded values being lower than the calculated, due to the absence of fire load at this point and a reduction in flame height. This result is something which is worth taking into consideration when using the EN 1991-1-2 to calculate flame temperatures during localised fires. These results are also set out in Table 1(a) and Table 1(b) respectively.

\section{FINITE ELEMENT ANALYSIS EXERCISES}

The thermal analaysis by TNO Diana is based on a three-dimensional steady state heat flow equation, which is given in Equation (5). This is derived from the law of conservation of energy, which states that 


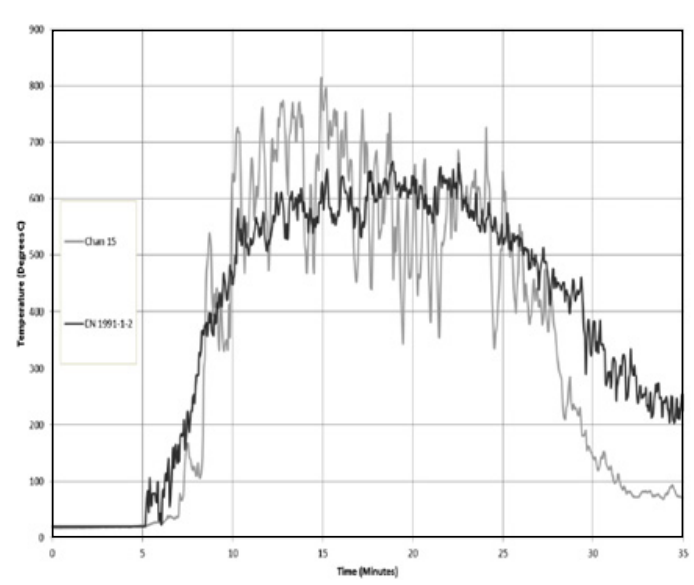

(a)

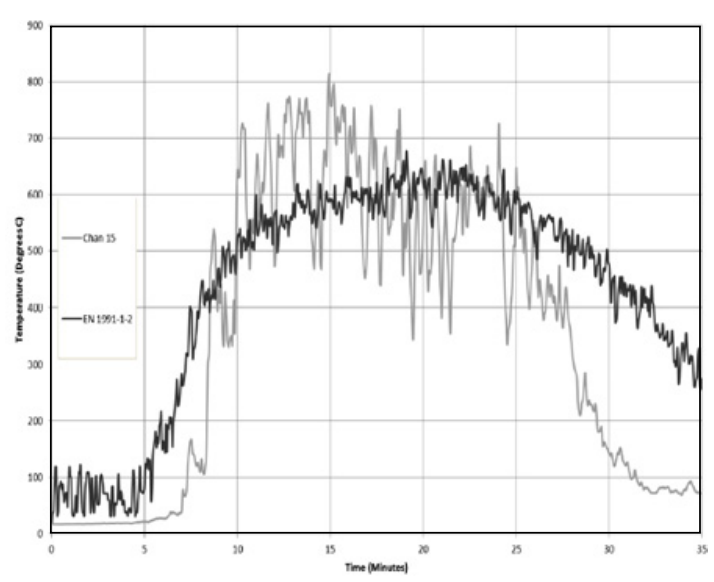

(b)

Figure 8. (a) Vertical and (b) inclined Euro-code and recorded mid flame temperature comparison.

Table 1. (a) Vertical and (b) inclined test EN 1991-1-2 calculation tables.

(a)

\begin{tabular}{ccc}
\hline $\begin{array}{c}\text { Time } \\
\text { Minutes }\end{array}$ & $\begin{array}{c}\text { Flame Temperature } \\
\left({ }^{\circ} \mathbf{C}\right)\end{array}$ & $\begin{array}{c}\text { EN 1991-1-2 } \\
\left({ }^{\circ} \mathbf{C}\right)\end{array}$ \\
\hline 0 & 17.04 & 20.00 \\
5 & 21.08 & 20.00 \\
10 & 643.25 & 447.29 \\
15 & 758.88 & 623.63 \\
20 & 545.99 & 624.21 \\
25 & 646.01 & 522.07 \\
30 & 142.47 & 373.02 \\
35 & 71.08 & 225.84 \\
\hline
\end{tabular}

(b)

\begin{tabular}{ccc}
\hline $\begin{array}{c}\text { Time } \\
\text { Minutes }\end{array}$ & $\begin{array}{c}\text { Flame Temperature } \\
\left({ }^{\circ} \mathbf{C}\right)\end{array}$ & $\begin{array}{c}\text { EN 1991-1-2 } \\
\left({ }^{\circ} \mathbf{C}\right)\end{array}$ \\
\hline 0 & 17.98 & 20.00 \\
5 & 216.35 & 84.49 \\
10 & 460.48 & 520.92 \\
15 & 656.22 & 593.67 \\
20 & 708.15 & 618.36 \\
25 & 153.38 & 584.56 \\
30 & 112.65 & 476.93 \\
35 & 57.87 & 274.74 \\
\hline
\end{tabular}

the total inflow of heat in a unit time accross a body must be equal to the total outflow per unit time.

$$
\frac{\delta}{\delta \mathrm{x}}\left(\mathrm{k} \frac{\delta \mathrm{T}}{\delta \mathrm{x}}\right)+\frac{\delta}{\delta \mathrm{y}}\left(\mathrm{k} \frac{\delta \mathrm{T}}{\delta \mathrm{y}}\right)+\frac{\delta}{\delta \mathrm{z}}\left(\mathrm{k} \frac{\delta \mathrm{T}}{\delta \mathrm{z}}\right)+\mathrm{Q}-\mathrm{c} \rho \frac{\delta \mathrm{T}}{\delta t}=0 .
$$

Where $\mathrm{k}$ is the thermal conductivity $(1.05 \mathrm{~W} / \mathrm{mK})$; $\mathrm{T}$ is the temperature gradient; $\rho$ is the density of the material $\left(2500 \mathrm{~kg} / \mathrm{m}^{3}\right)$; $\mathrm{c}$ is the specific heat of material $\left(2.20 \times 10^{2} \mathrm{~J} / \mathrm{kgK}\right)$; Q is the internally generated heat on unit volume per unit time; and $\mathrm{t}$ is time.

The effects of the time variable can be included directly and the solution of heat conduction equation is uniquely determined if an initial condition is given together with a boundary condition on part or all of the boundary or domain. The stiffness of a finite element is formulated with the assistance of material stifness matrix [D], which relates stresses to strains. With the addition of thermal stresses, the relation can be written as in Equation (6).

$$
\{\sigma\}=[D]\left\{\varepsilon-\varepsilon_{T}\right\}
$$

Numerical analysis findings in relation to the performance of glazing in fire presented by Quinn et al. [5], provides the researcher with confidence in the predictive capabilities of TNO Diana for 


\section{MATEC Web of Conferences}

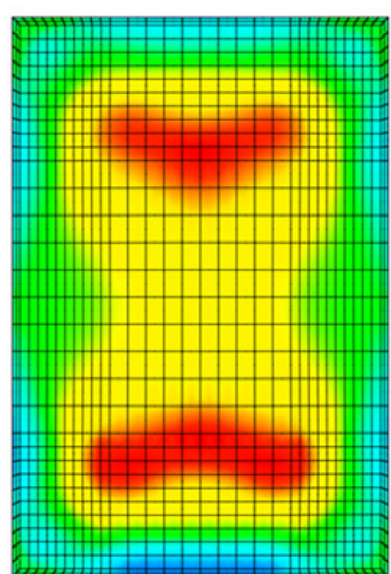

(a)

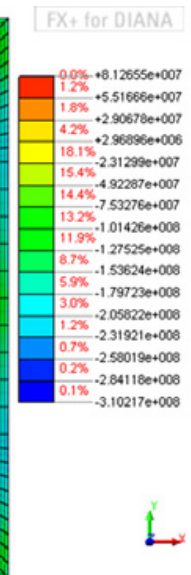

(1)

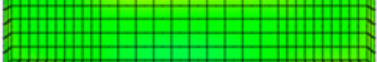

(b)

Figure 9. Vertical and (b) inclined model stresses 25.5 mins \& 17 mins (resin activation).

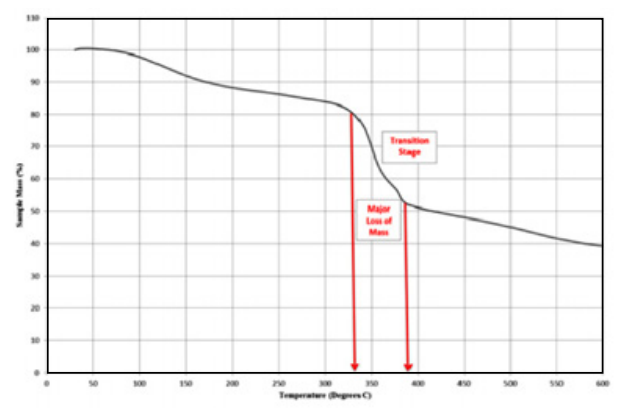

(a)

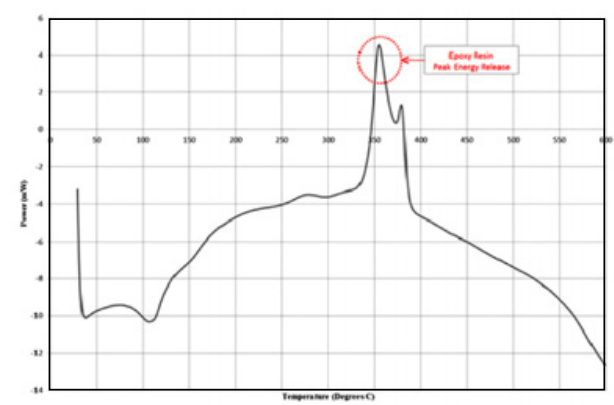

(b)

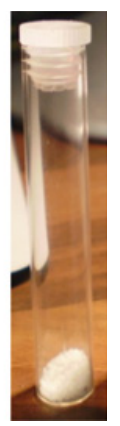

(c)

Figure 10. (a) TGA \& (b) DSC graphical output \& (c) pre-test epoxy resin sample.

glazing performance at elevated temperatures. Due to this previous success, 3D models replicating the test scenarios and the temperature data recorded in both the vertical and inclined tests have been implemented into the TNO Diana software and the stress concentrations in N/m $\mathrm{m}^{2}$ have been presented for both tests in Figure 10. In each test the impact of the flame in the localised fire scenario lead to the cracking of the glazing and the subsequent activation of the resin within the glazing panel. Due to this the stresses at resin activation time; vertical $\left(25.5 \mathrm{mins}: 8.13 \times 10^{7} \mathrm{~N} / \mathrm{m}^{2}\right)$ and inclined $(17 \mathrm{mins}$ : $9.56 \times 10^{7} \mathrm{~N} / \mathrm{m}^{2}$ ) are also presented in Figure 9 .

This finite element analysis work is a follow on from the research previously presented by Quinn et al. [5] and Tofilo et al. [6] into the stress generation in glazing systems as a result of the presence of non-uniform and uniform temperatures respectively. Figure 9 below includes finite element principal stress outputs for each test. It is clear from both stress patterns that both glazing panels are subjected to dramatically different fire scenarios, leading to different outcomes.

The finite element analysis exercises carried out are of enormous benefit in providing an understanding of the local stress generation as a result of the onslaught of localised fire on the vertical and inclined glazing. However an element of the scenario which requires greater analysis is that of the impact the transparent resin intermediate layer has on the overall glazing panel performance during fire. 
$1^{\text {st }}$ International Seminar for Fire Safety of Facades, Paris (France), 2013

Table 2. (a) TGA and (b) DSC tabulated output for epoxy resin sample tested.

(a)

\begin{tabular}{ccc|}
\hline $\begin{array}{c}\text { Time } \\
\text { Minutes }\end{array}$ & $\begin{array}{c}\text { Temperature } \\
{ }^{\circ} \mathbf{C}\end{array}$ & $\begin{array}{c}\text { Sample Mass } \\
\text { \% }\end{array}$ \\
\hline 0 & 30 & 100 \\
5 & 80 & 99.3539 \\
10 & 130 & 94.4108 \\
15 & 180 & 89.4424 \\
20 & 230 & 87.0037 \\
25 & 280 & 84.8178 \\
30 & 330 & 80.4458 \\
35 & 380 & 55.2088 \\
40 & 430 & 49.276 \\
45 & 480 & 46.4895 \\
50 & 530 & 43.0669 \\
\hline
\end{tabular}

(b)

\begin{tabular}{ccc}
\hline $\begin{array}{c}\text { Time } \\
\text { Minutes }\end{array}$ & $\begin{array}{c}\text { Temperature } \\
{ }^{\circ} \mathbf{C}\end{array}$ & $\begin{array}{c}\text { Power } \\
\mathbf{m W}\end{array}$ \\
\hline 0 & 30 & -3.24207 \\
5 & 80.1667 & -9.43057 \\
10 & 130.333 & -8.13135 \\
15 & 180.5 & -5.35327 \\
20 & 230.667 & -4.23531 \\
25 & 280.833 & -3.50507 \\
30 & 331 & -3.16137 \\
35 & 380 & 1.31762 \\
40 & 430.167 & -5.50744 \\
45 & 480.333 & -6.85893 \\
50 & 530.5 & -8.27674 \\
\hline
\end{tabular}

Once a greater understanding and knowledge of the resin properties is obtained, this knowledge will then be implemented into more advanced 3-dimensional finite element analysis models.

\section{MATERIAL ANALYSIS TESTING}

As stated above, in order to create more detailed finite element analysis models, a greater depth of knowledge is required in relation to the intermediate transparent resin layer within the tested glazing panels. This knowledge will be gained through the completion of detailed scientific material analysis tests on the transparent resin in the laboratory at FireSERT.

Thermo-gravimetric Analysis (TGA) [7] measures the amount and rate of change in the weight of a material as a function of temperature or time in a controlled atmosphere. Measurements are used primarily to determine the composition of materials and to predict their thermal stability at temperatures up to $1000^{\circ} \mathrm{C}$. The technique can characterize materials that exhibit weight loss or gain due to decomposition, oxidation, or dehydration. Differential Scanning Calorimetry (DSC) [7] is a thermal analysis technique that looks at how a material's heat capacity $(\mathrm{Cp})$ is changed by temperature. A sample of known mass is heated or cooled and the changes in its heat capacity are tracked as changes in the heat flow. This allows the detection of transitions like melts, glass transitions, phase changes, and curing.

Firstly from a review of the TGA results in Figure 10(a) which is a study of the mass loss of the epoxy resin as a function of temperature, it is clear that the curve begins to decend considerrably from about $80^{\circ} \mathrm{C}$, possibly due to evaporation of any internal moisture in the sample. The epoxy resin then experienced another dramatic reduction in mass at $300-350^{\circ} \mathrm{C}$, which it is reasonable to assume is the point of substansial deterioration of the sample. The epoxy resin sample is noted to have lost $50 \%$ of its original mass at $400^{\circ} \mathrm{C}$, and it had lost $60 \%$ of its original mass by $600^{\circ} \mathrm{C}$.

The DSC analysis of the epoxy resin sample in Figure 10(b) show a number of peaks and troughs which illustrate a number of phase changes and reaction types within the material upon heating. The endotherm occurring between $40-120^{\circ} \mathrm{C}$ show that the epoxy resin takes in energy from its surroundings in order to undergo initial change, which is though to be the evaporation of internal moisture as stated above. This endotherm is then gradually changed to an exotherm as the epoxy resin sample gives off energy as it undergoes significant degredation. The peak in this exotherm occurrs at $350^{\circ} \mathrm{C}$ which was the major transition/ degredation point as noted previously from the TGA result.

These two sets of material analysis results of the epoxy resin, which are also set out in tabulated format in Table $2 \mathrm{a} \& \mathrm{~b}$, demonstrate that any residual strength or ability to perform its function or mass disappears once it reaches temperatures in the region of $300-400^{\circ} \mathrm{C}$, following glazing cracking. On a 


\section{MATEC Web of Conferences}

positive note however at this point the resin material will have transformed from the initial transparent material to an opaque black material which in essence acts as a buffer to any heat attempting to transfer through the initially transparent glazing panel. This scenario can be seen in Figures 7a \& c above. These results will be of value in establishing thermal properties for advanced finite element analysis models of glazing sandwich panel performance at elevated temperatures.

\section{CONCLUSIONS \& RECOMMENDATIONS FOR FUTURE WORK}

- The composite glazing panels in both tests were subjected to the effects of localized fire, therefore considerable temperature variations existed in different points on the glazing panels, which play a key role in the initiation of glazing cracks.

- The variability in glazing performance between the vertical and inclined scenario was noted.

- The sandwich panels tested which are combinations of glazing and transparent resins have a vastly different reaction to elevated temperatures to that of the more conventional glazing.

- The final char patterns from both tests demonstrates to the reader the necessity for further investigation of the effects of localized fire on glazing systems, particularly the inclined scenario which is now very popular with building designers.

- The finite element analysis work presented in this paper requires further development, with the inclusion of more information on the transparent resin a necessity. The development of a more complete 3-dimensional model inclusive of the resin is ongoing at present at FireSERT.

\section{References}

[1] Pagni PJ and Joshi AA. "Glass Breaking in Fires", Fire Safety Science-Proc. Third International Symposium, 791-802, London Elsevier Applied Science; 1991.

[2] Shields TJ, Silcock GWH and Flood M, "Performance of a single glazing assembly exposed to a fire in the centre of an enclosure", Fire and Materials, 26(2), 51-75, 2002.

[3] Keski-Rahkonen O., "Breaking of Window Glass Close to Fire", Fire and Materials, 12(2), 61-69, 1998.

[4] Certifire, "CGI International Limited", Pyroguard, 2006-2016.

[5] Quinn M, Nadjai A, and Ali F, "Experimental and numerical investigation of inclined glazing façade performance under fire conditions", Proceedings of the 7th International Conference on Structures in Fire, 43-52, ETH Zurich, 6-8 June, 2012.

[6] Tofilo P, Delichatsios M, Nadjai A, and Franssen JM, "Thermal stresses in glazing systems in buildings", Proceedings of the $4^{\text {th }}$ International Workshop of Structures in Fire, 1065-1075, Aveiro, Portugal, 2006.

[7] Differential scanning Calorimetry and Thermo gravimetric analysis, "Fleming Polymer Testing and Consultancy" http://www.flemingptc.co.uk, 2008. 